\section{Sexual Disinhibition}

Irene Piryatinsky

Butler Hospital and Alpert Medical School of Brown University, Providence, RI, USA

\section{Definition}

Sexual disinhibition refers to socially or contextually inappropriate sexual behavior and is usually associated with frontal and temporal lobe pathology. There is some evidence that sexual disinhibition occurs due to the loss of cerebro-cortical inhibitor mechanisms, which results in the following behaviors: increased sexual interest, inappropriate cuddling, touching of the genitals, sexual propositions, grabbing and groping, use of obscene language, and masturbating in inappropriate settings without shame. Similar symptoms are noted in frontotemporal dementia, focal fronto-temporal lesions, mania, and following a seizure or treatment of Parkinson's disease.
Several medications, including antidepressants, anxiolytics, hormones, and lithium, have been used to treat sexual disinhibition.

\section{Cross-References}

- Kluver-Bucy Syndrome

- Parkinson's Disease

- Pick's Disease

\section{References and Readings}

Hashmi, F. H., Krady, A. I., Qayum, F., \& Grossberg, G. T. (2000). Sexually disinhibited behaviour in the cognitively impaired elderly. Clinical Geriatrics, 8(11), 61-68.

Nagaratnam, N., \& Gayagay, G. (2002). Hypersexuality in nursing care facilities: A descriptive study. Archives of Gerontology and Geriatrics, 35, 195-203.

Pilleri, G. (1966). The Kluver-Bucy syndrome in man: A clinico-anatomical contribution to the function of the medial temporal lobe structures. Psychiatria et Neurologia, 152, 65-103. 